\title{
Adapting services for autism: Recommendations from a specialist multidisciplinary perspective using freelisting
}

\author{
Stephanie Petty ${ }^{1,2}$ (ID $\cdot$ Milja-Leea Bergenheim ${ }^{1} \cdot$ Georgina Mahoney ${ }^{1} \cdot$ Lucy Chamberlain $^{1}$
}

Accepted: 1 July 2021 / Published online: 16 July 2021

(C) The Author(s) 2021

\begin{abstract}
The guidance available for tailoring mental health services for autistic people is limited and dispersed. Practitioners attempting to appropriately adapt mental healthcare and therapy provision report low confidence and inconsistency in their approach. This study contributes to the guidance by providing a shortlist of usable and priority adaptations for diagnostic and therapy services as described by multidisciplinary staff members responsible for the design and delivery of a specialist autism service in the UK. Individual freelisting interviews were conducted with 15 staff, who were asked to list the ways that they adapt their practice individually, within therapy, and collectively as a service. Salience and cultural consensus analyses demonstrated the following agreed priority service adaptations: ensuring the suitability of the service environment with consideration of sensory demands, adapting communication, knowing individual gender identity preferences and minimising client uncertainty. Detailed examples are given for flexibly adapting therapy to individual needs to inform general and specialist services. The findings require replication and evaluation.
\end{abstract}

Keywords Autism spectrum disorders · Therapy $\cdot$ Service design $\cdot$ Qualitative research

\section{Introduction}

Autism spectrum disorder (ASD), as defined by the Diagnostic and Statistical Manual of Mental Disorders (fifth edition, American Psychiatric Association, 2013), is a complex neurodevelopmental condition, associated with functional impairments and increased vulnerability to psychiatric comorbidities, including other developmental disorders, depression and anxiety (Lever \& Geurts, 2016). Psychiatric comorbidities play an important part in explaining discrepancies between cognitive abilities and adaptive functioning in autism (Kraper et al., 2017). The average lifetime cost of autism in the UK has been estimated at one million pounds (Buescher et al., 2014). Therefore, considering the impacts on an individual and at a societal level, it is necessary to ensure that adequate support is being provided for autistic people. Due to the clinical characteristics of autism, adjustments often need to be

Stephanie Petty

stephanie.petty@york.ac.uk

1 Department of Psychology, University of York, York YO10 5DD, UK

2 The Retreat York, Heslington Rd, York YO10 5BN, UK made to standard care, including ensuring that services are accessible and that therapy interventions across a range of modalities are appropriately tailored (National Institute for Health and Care Excellence, NICE, 2013, 2016). This study considers therapeutic support for autistic individuals without intellectual impairment.

With the diagnostic criteria encompassing many clinical subtypes, perhaps most characteristic of the autistic population is heterogeneity (Happé et al., 2006; Campisi et al., 2018). Gender is one important consideration: autism is estimated to affect between one and two percent of the population, with approximately three to four times higher male incidence (Loomes et al., 2017; Centers for Disease Control \& Prevention, 2020); diagnosis of autism is suggested to occur at a later stage for females, notably for those with mood disorders, higher intellectual ability and for those who camouflage their social communication difficulties (Dean et al., 2017; Rydzewska et al., 2019). Research indicates differences in the manifestations of autism in females that are inadequately captured by the current diagnostic standards (Beggiato et al., 2017; Campisi et al., 2018).

Due to both its core features and heterogeneity, several factors must be considered when tailoring diagnostic and therapy services for autistic people. Though prevalence rates are widely variable across studies, estimates suggest the vast 
majority of autistic children and adults will meet the diagnostic criteria for at least one other psychiatric disorder, at least once in their lifetime; over half of autistic people are estimated to have two or more co-occurring psychiatric diagnoses (Simonoff et al., 2008; Lever \& Geurts, 2016), with a high prevalence of mood disorders in particular (Hofvander et al., 2009; Lugo-Marín et al., 2019). In addition to high estimates of additional mental health needs across the lifespan, autism has been associated with lower quality of life, particularly in social and inter-personal domains (van Heijst \& Geurts, 2015; Hedley et al., 2018). Additionally, depression and anxiety are expected to be expressed atypically by autistic people, with symptoms of autism and mood disorders overlapping (Wigham et al., 2017; Bearss et al., 2016; Uljarević et al., 2018). Autism is associated with alexithymia, with important differences in the recognition and expression of negative thoughts and feelings (Bird \& Cook, 2013). Beyond alexithymia, different emotion regulation strategies, intolerance of uncertainty and sensory hyper- and hyposensitivities are thought to be autism-associated vulnerabilities to anxiety and mood disorders (Boulter et al., 2014; Maisel et al., 2016; Mazefsky et al., 2013; Wigham et al., 2015).

Paradoxically, many autism-associated mental health vulnerability factors present as challenges to accessing and benefitting from therapy interventions (Lumley et al., 2007; Renaud et al., 2014; Spain \& Happé, 2020). These challenges are not limited to the therapeutic process but extend to general aspects of many services, such as there being uncertainty and confusion at the point of service access, travel required to attend specialist services and in the increased demands on autistic clients to engage in novel and communicationfocused appointments (Cooper et al., 2018).

Despite this high priority context, the mental health needs of autistic people are not sufficiently met (Cadman et al., 2012; Murphy et al., 2018). Clinicians report limited experience and training in working with autistic people (Cooper et al., 2018; Ainsworth et al., 2020). Modifications that are made to therapy services are inconsistently applied (Ainsworth et al., 2020). Guidance on adapting services and interventions for autism is available within the UK (NICE, 2013, 2016; Department of Health, 2014) but there is little consistency reported across studies, thus offering no consensus for investment and demonstrating that there is missing detail in practice guidance. Furthermore, recommendations are mostly limited to adapting Cognitive Behavioural Therapy as one example of psychological therapy: a range of adaptations to standardised therapy practices have been described, including both omissions, such as focusing on behavioural aspects of psychological therapy with reduced emphasis on challenging negative thinking, and supplementary features, such as incorporating special interests into therapy (Spain et al., 2015; Walters et al., 2016). This means there is a restricted offer of therapy for autistic clients, omitting interventions provided by specialist autism services that focus on communication, sensory integration or occupation (Spain et al., 2015; Walters et al., 2016; Perihan et al., 2019). The variable suggestions offer something valuable to clinicians, and would benefit from replication and refinement.

Overall, the literature on providing therapeutic services for autistic clients offers no agreement on the priority adaptations for practice. NICE $(2013,2016)$ state it is necessary for autistic people to have access to a full range of mental health services, with local specialist multidisciplinary autism teams playing a key role in care delivery and coordination.

This study sought the agreed and prioritised recommendations for adapting therapy services for autistic clients by utilising the knowledge of a specialist autism service in the UK, offering guidance across therapies and in consideration of service accessibility and design. The aim was to inform service development within general and specialist mental health services for autistic clients.

\section{Methods}

\section{Participants}

Multidisciplinary staff members were recruited from a specialist autism service in the North of England, which provided diagnostic, post-diagnostic and therapeutic services for children, young people and adults. The service was funded both by the National Health Service to deliver contracted care, and privately funded care; the service was commissioned to support individuals without a diagnosed learning disability. 25 staff members from psychology, psychotherapy, speech and language therapy and occupational therapy disciplines, managerial and administrative roles were invited to participate. A total 15 members of staff volunteered.

\section{Materials}

A freelisting interview guide was used to structure individual interviews. Freelisting is a qualitative, ethnographic interviewing technique (Weller \& Romney, 1988) that allows members within a culture (here, staff members delivering a specialist autism service) to express their viewpoints and determine what is relevant and of most importance. Originally used in anthropological research, freelisting has been used in clinical research to explore mental health and mental healthcare (Martinez Tyson et al., 2011; Petty et al., 2020). Participants are asked to describe a particular domain (here, service adaptations for autism) by providing their responses to a series of questions in list format.

Participants were asked to keep in mind their routine experiences of working with autistic people and to provide spoken lists in response to the following questions: (1) the things you 
think are important to do, or the ways you adapt your practice, before you interact with somebody with autism; (2) any adaptations your service has made for people with autism; (3) any ways you adapt your practice, or the things you do differently, when you are with a person with autism; (4) any adaptations you make relating to a person's gender; (5) the things you think are important about the physical environment when working with a person with autism; (6) anything you would like to do differently if you were able to, thinking beyond resource constraints. No other prompts were provided. When participants indicated when they had completed the list, the interviewer proceeded to the next question. The questions were designed to allow participants to define what was most important in their routine working across different specialisms, whist being informed by the practice literature identifying gender identity and the physical environment of service delivery as important considerations.

\section{Procedure}

Interviews were conducted between April and July 2020. Participants provided written informed consent and demographic data. Interviews were conducted via video call, which was a routine way of working for the clinicians. Each freelisting interview lasted 20-25 min and was audio recorded. Recordings were transcribed in full and anonymised.

\section{Data Analysis}

Three researchers independently identified list items from each participant's interview transcript, removing conversational fillers. Each unique list item was allocated a three letter code. Codes were documented in a codebook for each interview question, which included a definition of the code and all variations of language considered synonymous for each code. In line with previous research (Schrauf \& Sanchez, 2008), answers were standardised so that listed derivatives of the same word (e.g. 'light' and 'lighting'), descriptions with synonymous meanings (e.g. 'eye contact not being so expected' and 'I might not make eye contact') were assigned the same code. Repeated list items were not coded as participants frequently summarised their lists. To retain the participant's original meaning, codebooks did not involve any thematic grouping so that every unique response to the question was retained and given a unique code (Weller \& Romney, 1988). A random sample of transcripts $(10 \%)$ was coded by an independent reviewer to improve the validity of the abbreviated lists (Petty et al., 2020). Agreement between researchers across the six codebooks was 77-85\%. Ambiguities were resolved through group discussion or the participant's verbatim description was retained and given a unique code.

\section{Freelisting Analysis}

Participants' listed responses to the six interview questions, represented as three letter codes, formed the dataset for the analysis. List answers were written in ASCII computer language and saved as .txt files. Using ANTHROPAC software (Borgatti, 1996a), the data for each interview question was analysed in turn using the following stages:

1. ANTHROPAC freelisting functions were used to calculate the frequency and salience of each list item. Salience (Smith's S) is a measure from 0 to 1.0 that indicates the relative importance of a list item. It is calculated based on the relative length of the list, the rank position of the item in the list and the frequency of the item being listed across participants; more salient items are listed more frequently and earlier in participant lists (Smith \& Borgatti, 1998). Item salience scores were then plotted using a scree curve to allow for visual detection of the breaking point between items that were culturally shared and those reflecting individual preferences. Consistent with previous research (Barg et al., 2006; Petty et al., 2020), only salient items above the identified inflection point, and mentioned by at least $20 \%$ of the participants, were considered within the boundaries of a cultural definition, representing adaptations to practice that staff members within the service agreed upon.

2. To describe the extent of agreement between particpants, cultural consensus analysis was conducted. ANTHROPAC recoding functions were used to organise the data into a participant-by-item-matrix where all matrix cells containing a list item were coded as 1 and those not containing a list item as 0 . Consensus analysis was then conducted to test whether the data was representative of one unitary bounded cultural domain using minimal residual factor analysis. Treating participants as variables and list items as cases (a participant-by-participant-matrix), the analysis weights the response patterns of each participant against the most common response patterns in the group; the resultant factors represent the level of consensus within the group (Borgatti, 1996b). A single-factor solution, meaning an agreed response to the interview question, is indicated by a ratio between the first and second eigenvalues of above 3:1(Borgatti, 1996b). A knowledge score from 0 to 1.0 for each participant shows the loadings of each participant's responses on the first factor.

In recognition of the richness of the answers provided, the 10 most salient items for each question are presented. Items meeting the threshold for cultural consensus are indicated in the results tables. 


\section{Compliance with Ethical Standards}

Ethical approval was granted by the University of York Psychology Department Ethics Committee and by the The Retreat York's research governance group.

\section{Community Involvement}

All study materials were revised by an expert by experience with autism, including the outcome measures, the design of the study and the interpretation of the findings.

\section{Results}

\section{Participant Characteristics}

The majority of participants were female (80\%), White British (73\%) and aged between 25 and 34 and 35-44 years. The sample included the following professional roles: clinical psychologist $(n=5)$, assistant psychologist $(n=2)$, speech and language therapist $(\mathrm{n}=2)$, occupational therapist $(n=1)$, senior psychotherapist $(n=1)$, medical secretary $(n=1)$, senior administrator $(n=1)$, chief officer of clinical services $(\mathrm{n}=1)$ and customer relations manager $(\mathrm{n}=1)$. Mean duration of working with autistic people was six years $(\mathrm{SD}=$ 4.2), ranging from seven months to 14 years. All but one participant reported training in working with autistic people, including informal work-based training with peers, training in using specialised assessment tools and post-graduate level training. Over half of the participants (53\%) reported having a family member or friends with an autism diagnosis.

\section{Responses to Freelisting Questions}

The 10 most salient items for each interview question, their frequency and average rank position within participants' lists are shown in Tables 1, 2 3, 4, 5, 6 .

\section{Question 1: Adapted Practice Before Meeting with an Autistic Client}

Collectively, participants gave 104 unique responses, or listed items, to this question. The mean list length was 11 items (SD $=4.8)$. The ratio between the first (9.36) and second (0.42) eigenvalue was beyond the 3:1 ratio, meaning the responses given were representative of one bounded cultural domain: an agreed description of shared practice. The average knowledge score across participants was $.79(\mathrm{SD}=.09)$ indicating relatively high agreement among participants. Five listed items met the threshold for cultural consensus and demonstrate the shared priority adaptations, as shown in Table 1. Although listed sixth on average, listed by $60 \%$ of the participants, checking the suitability of the environment was the most salient item for Question 1. Across all the questions, the longest lists and the highest number of unique list items were provided for Question 1.

\section{Question 2: Service Level Adaptations}

Participants gave 60 unique list items. The mean list length was eight items $(\mathrm{SD}=3.7)$. A ratio above $3: 1$ between the first (8.54) and second (0.63) eigenvalues supported the presence of a single unified domain. Participants' average knowledge score was $.75(\mathrm{SD}=.11)$. Nine adaptations within the boundaries of a cultural definition are shown in Table 2; question 2 generated the highest number of culturally shared items, likely reflecting the expertise of the full participant sample across different professions. Creating a sensory-friendly environment was the most salient item for Question 2, listed on average third and by $53 \%$ of participants.

\section{Question 3: Adaptations within a Client Appointment}

Participants gave 78 unique list items. The mean list length was nine items $(\mathrm{SD}=3.7)$. The ratio between the first $(9.09)$ and the second (0.84) eigenvalues was above 3:1, thus the answers were reflective of one coherent cultural domain. Participants' average knowledge score was $.77(\mathrm{SD}=.09)$. Three items met the threshold for cultural consensus, shown in Table 3. Listed by $60 \%$ of participants and mentioned on average second, communicating clearly, was the most salient item for Question 3. Though fewer items were agreed by all staff members, the 10 most salient items listed were relatively high in salience when compared with other questions, showing a wider pool of possible adaptations, applied more variably across clinicians.

\section{Question 4: Consideration of Gender}

Participants listed 20 unique list items. The mean list length was four items $(\mathrm{SD}=2.1)$. With the ratio from the first eigenvalue (8.15) to the second (1.52) being above $3: 1$, one bounded cultural domain was represented. Participants' average knowledge score was .71 (SD = .20). Five items met the threshold for cultural consensus, as shown in Table 4 . Listed by $60 \%$ of the participant and on average second in a participant's answer, knowing how someone identifies their gender and having an awareness of autistic gender differences were respectively the first and second most salient items for Question 4. Of all questions, the shortest lists and the lowest number of unique items were provided for this question, suggesting fewer agreed practice adaptations. 
Table 1 The most salient responses to Question (1) Adapted practice before attending an appointment with an autistic client

\begin{tabular}{|c|c|c|c|c|c|}
\hline List item & Description of list item & Frequency & $\begin{array}{l}\text { Listed } \\
\text { by }(\%)\end{array}$ & $\begin{array}{l}\text { Average } \\
\text { rank }\end{array}$ & Salience \\
\hline $\begin{array}{l}\text { Check the suitability } \\
\text { of the sensory } \\
\text { environment }\end{array}$ & $\begin{array}{l}\text { Considering environment suitability; } \\
\text { included checking the sensory } \\
\text { environment and removing } \\
\text { irritable or overwhelming things } \\
\text { where possible. }\end{array}$ & 9 & 60 & 6.2 & $.334 *$ \\
\hline $\begin{array}{l}\text { Find out about the } \\
\text { client in advance }\end{array}$ & $\begin{array}{l}\text { Finding out about the client in } \\
\text { advance; included current } \\
\text { wellbeing and priorities and } \\
\text { checking notes about their gender } \\
\text { preferences. }\end{array}$ & 5 & 33 & 1.6 & $.306 *$ \\
\hline $\begin{array}{l}\text { Be clear in } \\
\text { communication }\end{array}$ & $\begin{array}{l}\text { Communicating clearly; included } \\
\text { descriptions of being black and } \\
\text { white, using simple and concise } \\
\text { language or giving salient } \\
\text { summary points. }\end{array}$ & 5 & 33 & 4.6 & $.206 *$ \\
\hline $\begin{array}{l}\text { Check suitability of } \\
\text { lighting }\end{array}$ & $\begin{array}{l}\text { Considering lighting suitability, } \\
\text { brightness or harshness. }\end{array}$ & 5 & 33 & 7.6 & $.179 *$ \\
\hline $\begin{array}{l}\text { Ensure the client is } \\
\text { prepared for } \\
\text { what will happen }\end{array}$ & $\begin{array}{l}\text { Ensuring the client is prepared for } \\
\text { what is going to happen or what } \\
\text { questions will be asked during the } \\
\text { session. }\end{array}$ & 3 & 20 & 3.0 & $.168 *$ \\
\hline $\begin{array}{l}\text { Find out if the client } \\
\text { has sensory needs }\end{array}$ & $\begin{array}{l}\text { Understanding if the client has } \\
\text { sensory needs. }\end{array}$ & 4 & 27 & 6.3 & .141 \\
\hline $\begin{array}{l}\text { Be prepared to adjust } \\
\text { communication }\end{array}$ & $\begin{array}{l}\text { Descriptions of being prepared to } \\
\text { change and adjust communication } \\
\text { included having information } \\
\text { available in different formats or } \\
\text { being able to explain things in a } \\
\text { different way. }\end{array}$ & 3 & 20 & 4.3 & .141 \\
\hline $\begin{array}{l}\text { Find out about the } \\
\text { client in advance } \\
\text { from significant } \\
\text { people }\end{array}$ & $\begin{array}{l}\text { Finding out about the client in } \\
\text { advance from family, teachers, } \\
\text { carers or other significant people. }\end{array}$ & 3 & 20 & 5.3 & .139 \\
\hline $\begin{array}{l}\text { Find out about the } \\
\text { client in advance } \\
\text { from case notes }\end{array}$ & $\begin{array}{l}\text { Finding out about the client in } \\
\text { advance specifically by reading } \\
\text { case notes or diagnostic reports. }\end{array}$ & 2 & 13 & 1.5 & .129 \\
\hline $\begin{array}{l}\text { Ensure the client is } \\
\text { prepared about the } \\
\text { purpose of the } \\
\text { appointment }\end{array}$ & $\begin{array}{l}\text { Ensuring the client knows what the } \\
\text { purpose of the session is; } \\
\text { including descriptions about why } \\
\text { they are there and ensuring } \\
\text { consent. }\end{array}$ & 2 & 13 & 3.0 & .117 \\
\hline
\end{tabular}

Salient items marked by * and in bold are considered to be consensus responses to the question

\section{Question 5: Adaptations Made in the Physical Environment}

Participants gave 48 unique list items. The mean list length was eight items $(\mathrm{SD}=3.7)$. A ratio greater than $3: 1$ between the first (7.60) and second (0.93) eigenvalues supported the presence of one unified cultural domain. Participants' average knowledge score was .70 (SD = .12). The four most salient items within the boundaries of a cultural definition are shown in Table 5. Consideration of noise was the most salient item across all six interview questions, demonstrating a priority adaptation amongst staff members.

\section{Question 6: Priority Adaptations for Further Investment}

Participants gave 39 unique list items. The mean list length was four items $(\mathrm{SD}=1.9)$. With an above 3:1 ratio between the first (8.15) and second (0.59) eigenvalues, the answers reflected one coherent cultural domain. The average knowledge score was $.77(\mathrm{SD}=.11)$. The seven most salient items meeting the threshold for cultural consensus are shown in Table 6. Although multidisciplinary team working and having access to improved technologies and other resources were both listed by the highest number of participants (27\%), individualising client sessions, such as the length or frequency 
Table 2 The most salient responses to Question (2) Service level adaptations

\begin{tabular}{|c|c|c|c|c|c|}
\hline List item & Description of list item & Frequency & Listed by $(\%)$ & $\begin{array}{l}\text { Average } \\
\text { rank }\end{array}$ & Salience \\
\hline Provide a sensory friendly environment & Reducing sensory input to reduce overwhelm. & 8 & 53 & 2.6 & $.448 *$ \\
\hline $\begin{array}{l}\text { Make information available for } \\
\text { clients about the service }\end{array}$ & $\begin{array}{l}\text { Available information included leaflets, information } \\
\text { packs or documents about the service and what to } \\
\text { expect from a visit. This included photographs } \\
\text { showing clients where they are going or who they } \\
\text { will meet. }\end{array}$ & 7 & 46 & 4.1 & $.346^{*}$ \\
\hline Ensure suitable noise levels & $\begin{array}{l}\text { Controlling noise included minimising sounds outside } \\
\text { the building, using quieter rooms, having quiet } \\
\text { waiting rooms or minimising noise from phones, } \\
\text { clocks or equipment inside the building. }\end{array}$ & 8 & 53 & 4.4 & $.334 *$ \\
\hline Adapt communication & $\begin{array}{l}\text { Being aware of communication with clients meant } \\
\text { communicating clearly informed by an } \\
\text { understanding of autism. }\end{array}$ & 6 & 40 & 4.7 & $.244 *$ \\
\hline Keep to plain design & $\begin{array}{l}\text { Keeping things plain or neutral included minimal } \\
\text { decoration and uncluttered rooms or walls. }\end{array}$ & 5 & 33 & 3.4 & $.230 *$ \\
\hline Offer flexible session timings & $\begin{array}{l}\text { Being flexible with appointments included breaking } \\
\text { appointments or having shorter sessions. }\end{array}$ & 5 & 33 & 3.2 & $.203^{*}$ \\
\hline $\begin{array}{l}\text { Maintain the specialist } \\
\text { skillset of staff }\end{array}$ & $\begin{array}{l}\text { Having skilled or trained staff was described, } \\
\text { including staff being skilled to communicate } \\
\text { clearly and understand the needs of people } \\
\text { with autism. }\end{array}$ & 4 & 27 & 2.8 & $.181 *$ \\
\hline Adapt written correspondence & $\begin{array}{l}\text { Written correspondence included clear and } \\
\text { specific written communication or references to } \\
\text { letters with information, checked by experts by } \\
\text { experience. }\end{array}$ & 3 & 20 & 2.0 & $.181 *$ \\
\hline Utilise a protected building or space & $\begin{array}{l}\text { Having a designated building or space for autism } \\
\text { services ensured design and environment } \\
\text { decisions could be maintained. }\end{array}$ & 3 & 20 & 2.0 & $.167 *$ \\
\hline Use signs up to modify the environment & $\begin{array}{l}\text { Signs encouraged clients to adjusts their environment, } \\
\text { for example to shut the blinds or turn music off. }\end{array}$ & 3 & 20 & 3.3 & .134 \\
\hline
\end{tabular}

Salient items marked by * and in bold are considered to be consensus responses to the question

of sessions, and having a suitable building for a specialist autism service, were respectively the most and second most salient items for Question 6, both listed by $20 \%$ of the participants and on average in first position. Compared with other questions, agreed items listed for Question 6 were relatively low in salience, showing lower agreement on possible future improvements when compared with current routine practice priorities.

\section{Results Summary}

For all six interview questions, consensus analyses demonstrated a shared description of adapted practice from the multidisciplinary staff team across full service working: results present a consensus on the priority adaptations made in delivering diagnostic and therapeutic mental health services for autistic people. This finding suggests that specialist knowledge is held by the service. Staff members demonstrated consistently high agreement across all aspects of service delivery, in preparation for meeting a client, within interpersonal interactions and in the design of the service environment and systems. Staff members offered the highest number of possible adaptations for when preparing to meet with an autistic client, such as preparing the environment, learning about the client's needs and preferences in advance and helping to reduce client uncertainty around what to expect. Creating a sensory-friendly environment and reducing noise were the highest priority adaptations across all questions. Overall, the results are consistent with the notion of specialist knowledge of autism being part of routine practice within specialist services in their adapting of care for autistic clients.

\section{Discussion}

Research into the best ways to tailor therapeutic services for autistic people has been without consensus on the priority adaptations for practice (Ainsworth et al., 2020; Spain \& Happé, 2020; Walters et al., 2016), notably, adaptations that could improve engagement with a range of therapeutic 
Table 3 The most salient responses to Question (3) Adaptations within a client appointment

\begin{tabular}{|c|c|c|c|c|c|}
\hline List item & Description of list item & Frequency & Listed by $(\%)$ & Average rank & Salience \\
\hline Communicate clearly & $\begin{array}{l}\text { Using clear, direct, firm, concrete or verbally explicit } \\
\text { communication, language, or requests. Also included } \\
\text { adapting communication to client's language profile } \\
\text { or avoiding jargon. }\end{array}$ & 9 & 60 & 2.0 & $.536 *$ \\
\hline Avoid ambiguity & $\begin{array}{l}\text { Avoiding ambiguity or ambiguous expressions in } \\
\text { communication, including non-literal or figurative } \\
\text { language. }\end{array}$ & 4 & 27 & 2.5 & $.231 *$ \\
\hline $\begin{array}{l}\text { Offer a flexible and } \\
\text { individualised approach }\end{array}$ & $\begin{array}{l}\text { Adapting to each individual, including using techniques } \\
\text { known to work them. }\end{array}$ & 5 & 33 & 5.0 & $.204 *$ \\
\hline Check for understanding & Checking that the client understands or has understood. & 4 & 27 & 4.8 & .180 \\
\hline $\begin{array}{l}\text { Agree etiquette for making } \\
\text { eye contact }\end{array}$ & $\begin{array}{l}\text { Reducing, avoiding or not expecting eye contact; thinking } \\
\text { or asking clients about their eye contact preferences. }\end{array}$ & 4 & 27 & 3.5 & .177 \\
\hline Slow the pace of communication & $\begin{array}{l}\text { Communicating more slowly, including thinking about } \\
\text { talking pace or giving clients more time to process } \\
\text { language. }\end{array}$ & 3 & 20 & 2.7 & .169 \\
\hline Avoid idioms & $\begin{array}{l}\text { Avoiding idioms in communication. This include giving } \\
\text { examples of idioms with explanation of avoiding } \\
\text { such language. }\end{array}$ & 3 & 20 & 3.3 & .159 \\
\hline Monitor own communication & $\begin{array}{l}\text { Descriptions of being aware of one's own } \\
\text { communication, including communication styles } \\
\text { and skills, pragmatic communication. }\end{array}$ & 3 & 20 & 3.0 & .156 \\
\hline $\begin{array}{l}\text { Consider the room seating } \\
\text { arrangement }\end{array}$ & $\begin{array}{l}\text { Considering room seating arrangements, including } \\
\text { where to sit, letting the client choose their seat or } \\
\text { checking they are comfortable with seating closeness. }\end{array}$ & 3 & 20 & 3.3 & .152 \\
\hline Use agendas & $\begin{array}{l}\text { Utilising or giving the option of an agenda, sometimes } \\
\text { specified as a written or visual agenda, or using visual } \\
\text { strategies to explain session structure. }\end{array}$ & 4 & 27 & 6.5 & .151 \\
\hline
\end{tabular}

Salient items marked by * and in bold are considered to be consensus responses to the question

interventions, for clients across the age range from childhood to adulthood have been missing from practice guidance. This study directly responded to best practice guidance by seeking advice from a specialist autism service in the UK by asking how the specialist service adapts practice for individuals with autism to provide appropriate, tailored care.

First, the findings demonstrate agreed priority adaptations to practice across six service areas and a breadth of specialist knowledge. Similar to previous research (Petty et al., 2020), the high and consistent participant knowledge scores demonstrated across the questions is consistent with the notion of a specialist service with high levels of shared expertise being described by a range of healthcare professionals. Second, the findings present a shortlist of priority adaptations that are relevant for full-service design. Across all questions, priority adaptations were in four areas. These were: creating a customised environment, adapting communication at all levels of service delivery, reducing uncertainty from the first point of access and individualising care provision. These recommendations were for child and adult clients.

Over a third of all priority adaptations promoted an autismfriendly environment. Examples of environmental adaptations in the set-up of the service included providing adjustable lighting, choosing a neutral colour scheme and choosing less intrusive scented products and noise-causing equipment such as phones and clocks. Within day-to-day care delivery, staff members chose clinic rooms less impacted by weather and traffic. Clients were advised to modify the environment including closeness and orientation to the clinician. These recommendations are responsive to the high prevalence of sensory processing difficulties for autistic people (Crane et al., 2009; Leekam et al., 2007; Simpson, 2016) and the suggested negative impacts of these on engaging with therapy (Cooper et al., 2018; Maddox et al., 2020). The recommendations are summarised here to be a necessary and priority consideration when providing therapy services for autistic people. The current study gives more weight to the immediate and disruptive impacts of an inappropriate environment, with relevance to any therapeutic intervention or appointment. The modifications are an important addition to the literature in being specific and actionable (Spain \& Happé, 2020).

The reported adaptations to communication were focused on reducing ambiguity, hence the cognitive demand on clients to imagine and to perspective-take. Consistent with previous recommendations for therapy services, practitioners said they choose simple and concise language, avoid ambiguous, non- 
Table 4 The most salient responses to Question (4) Consideration of gender

\begin{tabular}{|c|c|c|c|c|c|}
\hline List item & Description of list item & Frequency & $\begin{array}{l}\text { Listed } \\
\text { by }(\%)\end{array}$ & $\begin{array}{l}\text { Average } \\
\text { rank }\end{array}$ & Salience \\
\hline $\begin{array}{l}\text { Know how someone } \\
\text { identifies }\end{array}$ & $\begin{array}{l}\text { Knowing, asking or checking the gender someone identifies with. Descriptions } \\
\text { included awareness of people identifying in many ways in terms of gender. }\end{array}$ & 9 & 60 & 1.9 & $.444 *$ \\
\hline $\begin{array}{l}\text { Maintain awareness of } \\
\text { gender differences }\end{array}$ & $\begin{array}{l}\text { Being aware that autism can present in many ways; majority of participants } \\
\text { described female presentations of autism and masking, with elaborations } \\
\text { suggesting this is not explicitly tied to client sex. }\end{array}$ & 9 & 60 & 2.4 & $.406^{*}$ \\
\hline $\begin{array}{l}\text { There are no known } \\
\text { adaptations }\end{array}$ & $\begin{array}{l}\text { Descriptions of having no known adaptations for gender, including not making } \\
\text { adaptations, treating everybody the same, not referring to gender or not being } \\
\text { able to name any adaptations. }\end{array}$ & 7 & 47 & 2.3 & $.322 *$ \\
\hline $\begin{array}{l}\text { Do not make } \\
\text { assumptions }\end{array}$ & $\begin{array}{l}\text { Not making assumptions, having no expectations or being open-minded around } \\
\text { gender, gender identity, sexuality or ways of addressing clients. }\end{array}$ & 5 & 33 & 2.6 & $.243 *$ \\
\hline $\begin{array}{l}\text { Know pronoun or } \\
\text { name preferences }\end{array}$ & $\begin{array}{l}\text { Descriptions included knowing, asking, checking or using the preferred pronouns, } \\
\text { names or terminology. }\end{array}$ & 6 & 40 & 2.7 & $.230 *$ \\
\hline $\begin{array}{l}\text { Use a preference } \\
\text { notifications system }\end{array}$ & $\begin{array}{l}\text { Using a computer system where gender and associated preferences can be added } \\
\text { as visible notifications for all staff. }\end{array}$ & 2 & 13 & 1.5 & .126 \\
\hline $\begin{array}{l}\text { Maintain awareness of } \\
\text { gendered socialisation }\end{array}$ & $\begin{array}{l}\text { Being aware that people are socialised in different ways regarding gender; that } \\
\text { gender can influence one's life experiences. }\end{array}$ & 2 & 13 & 2.5 & .100 \\
\hline $\begin{array}{l}\text { Check suitability of } \\
\text { clinician gender }\end{array}$ & $\begin{array}{l}\text { Ensuring a client is comfortable with the clinician's gender; offering a chaperone } \\
\text { or a different therapist. }\end{array}$ & 2 & 13 & 3.0 & .083 \\
\hline $\begin{array}{l}\text { Adapt questioning for } \\
\text { female representation }\end{array}$ & Going beyond standard questions in an assessment. & 2 & 13 & 3.0 & .067 \\
\hline $\begin{array}{l}\text { Offer gender appropriate } \\
\text { resources }\end{array}$ & $\begin{array}{l}\text { Ensuring that any resources used are appropriate for the gender a client identifies } \\
\text { with. }\end{array}$ & 1 & 7 & 1.0 & .067 \\
\hline
\end{tabular}

Salient items marked by * and in bold are considered to be consensus responses to the question

Table 5 The most salient responses to Question (5) Adaptations made in the physical environment

\begin{tabular}{|c|c|c|c|c|c|}
\hline List item & Description of list item & Frequency & $\begin{array}{l}\text { Listed } \\
\text { by }(\%)\end{array}$ & $\begin{array}{l}\text { Average } \\
\text { rank }\end{array}$ & Salience \\
\hline Reduce noise & Included choosing quieter rooms, avoiding flapping blinds or tapping a pen. & 12 & 80 & 3.8 & $.559 *$ \\
\hline $\begin{array}{l}\text { Provide adjustable } \\
\text { lighting }\end{array}$ & Included trying to offer natural lighting or a range of lamp/lighting options. & 9 & 60 & 3.6 & $.442 *$ \\
\hline Neutralise decor & $\begin{array}{l}\text { A neutral colour scheme avoided bright colours for the walls, furniture, carpets, } \\
\text { clothing or accessories. }\end{array}$ & 7 & 47 & 4.4 & $.306^{*}$ \\
\hline Offer space & $\begin{array}{l}\text { Choice was given to clients where possible of the size and layout of the room, } \\
\text { especially for psychological therapy sessions; choice was given on seating } \\
\text { arrangement. }\end{array}$ & 6 & 40 & 2.7 & $.279 *$ \\
\hline Reduce scents & $\begin{array}{l}\text { Cooking or food smells were considered; strong disinfectants or air fresheners } \\
\text { were avoided. }\end{array}$ & 5 & 33 & 5.4 & .200 \\
\hline $\begin{array}{l}\text { Neutralise all sensory } \\
\text { demands }\end{array}$ & $\begin{array}{l}\text { A plain and neutral sensory environment was described, including reflecting on } \\
\text { possible sensory demands. }\end{array}$ & 4 & 27 & 4.0 & .172 \\
\hline Control outside noise & $\begin{array}{l}\text { Lawn mowers, traffic, maintenance works, simultaneous appointments and open } \\
\text { windows were each described as noises to manage. }\end{array}$ & 5 & 33 & 6.2 & .162 \\
\hline Avoid patterns & $\begin{array}{l}\text { Patterns in the environment, including on walls, carpets or clothes, were } \\
\text { avoided. }\end{array}$ & 3 & 20 & 3.3 & .144 \\
\hline $\begin{array}{l}\text { Reduce the number of } \\
\text { items in the } \\
\text { environment }\end{array}$ & Practitioners maintained a minimal amount of objects within each room. & 3 & 20 & 4.3 & .138 \\
\hline Provide sensory resources & Sensory or fidget toys were available. & 4 & 27 & 6.0 & .129 \\
\hline
\end{tabular}

Salient items marked by * and in bold are considered to be consensus responses to the question 
Table 6 The most salient responses to Question (6) Priority adaptations for further investment

\begin{tabular}{|c|c|c|c|c|c|}
\hline List item & Description of list item & Frequency & Listed by $(\%)$ & $\begin{array}{l}\text { Average } \\
\text { rank }\end{array}$ & Salience \\
\hline Individualising sessions & $\begin{array}{l}\text { Included offering different session lengths or frequencies, } \\
\text { often dictated by funding. }\end{array}$ & 3 & 20 & 1.0 & $.200 *$ \\
\hline Accessing a bespoke service building & Included having larger rooms. & 3 & 20 & 1.3 & $.178^{*}$ \\
\hline Improving service resources & $\begin{array}{l}\text { Included having improved technology for presentations } \\
\text { or access to whiteboards. }\end{array}$ & 4 & 26 & 3.3 & $.175^{*}$ \\
\hline Increasing post diagnostic support & $\begin{array}{l}\text { Including support for families or post-diagnostic support } \\
\text { groups. }\end{array}$ & 3 & 20 & 2.0 & $.167 *$ \\
\hline Clinician training & $\begin{array}{l}\text { Providing formal autism training to all staff and ensuring } \\
\text { all training is up to date. }\end{array}$ & 3 & 20 & 3.0 & $.138 *$ \\
\hline Multi-disciplinary team working & $\begin{array}{l}\text { Having more multi-disciplinary or multiagency team } \\
\text { meetings. Descriptions included being able to work } \\
\text { collaboratively within and outside of the service. }\end{array}$ & 4 & 27 & 2.8 & $.122 *$ \\
\hline Soundproofing & Better soundproofing in all spaces. & 2 & 13 & 1.5 & .122 \\
\hline Accessing variable spaces & Having access to outside space including for therapy. & 2 & 13 & 2.5 & .089 \\
\hline Improving access for disabilities & $\begin{array}{l}\text { Issues with stairs and wheelchair accessibility } \\
\text { were described. }\end{array}$ & 2 & 13 & 2.5 & .087 \\
\hline Improving the waiting area & $\begin{array}{l}\text { A larger waiting area or multiple waiting spaces were } \\
\text { described, to accommodate clients and families. }\end{array}$ & 3 & 20 & 4.3 & .082 \\
\hline
\end{tabular}

Salient items marked by $*$ and in bold are considered to be consensus responses to the question

literal or figurative language, use structure and agenda-setting within appointments and present information in different formats (Department of Health, 2014; Simpson, 2016; Cooper et al., 2018; Maddox et al., 2020). This study adds the following recommendations: for communication to include consideration of gender preferences, such as pronoun use in written communication and having electronic note alert systems to avoid errors across team members; allowing more time for clients to process language in every communication across service staff, checking understanding, and using visual prompts to structure and summarise interactions; consideration of written correspondence and wording of letters with careful review by experts; consideration of building signage to reduce client uncertainty of where to go and what to do; all staff members reflecting on their use of language through reflective practice and team learning. In turn, this equates to a shared culture of suitable communication (Simpson, 2016).

Staff members also prioritised practice that reduces client uncertainty. Namely, practitioners said they ensure a client is prepared for what is going to happen by providing preparatory information about the service in the format of maps, photographs and descriptions, and preparatory information about clinical sessions, such as providing advance questions. These adaptations add to existing recommendations for therapy-specific modifications (Walters et al., 2016; Cooper et al., 2018). This is an important consideration given intolerance of uncertainty in autism and its links to psychiatric comorbidities, anxiety in particular (Maisel et al., 2016; Boulter et al., 2014).

Heterogeneity of the autistic population and important impacts of delayed diagnosis and psychiatric comorbidity requires responsive and individualised service provision (Beggiato et al., 2017; Happé et al., 2006; Hull et al., 2020). The fourth area of prioritised service adaptation in this study was the implementation of shared multidisciplinary expertise to tailor care. Examples were the interpretation of standardised assessment tools for consideration of gender (Hull et al., 2020), the expectation of heterogeneity in gender identity and in relational or sexual preferences (Dewinter et al., 2017); knowing each client (Ainsworth et al., 2020) and flexibility in the duration and timings of clinical appointments were also prioritised. The lack of consensus in adaptations for autism may be partly reflective of this need for variability (Walters et al., 2016), as has been articulated personally by autistic adults (Maddox et al., 2020). It is also consistent with the broadening understanding of autism as a spectrum condition (Frith \& Happé, 2005; Lord et al., 2020). Moreover, although research on autism and gender is its infancy, practitioners working with open mindedness around gender and awareness of the many ways autism can present are important considerations when working with autistic people (Skagerberg et al., 2015; Dewinter et al., 2017; Hull et al., 2020).

In addition to presenting the adaptations prioritised in current practice, areas for improvement were discussed as follows: having increased time to invest in staff training, 
increasing post-diagnostic support for autistic clients, coordinating a range of interventions with providers outside of the service, such as with employers or educators, and working collaboratively across professions to offer more multidisciplinary interventions, including speech and language assessments or workplace support. These future directions reflect the economic and policy contexts of autism when individuals are not able to reach their potential in education, employment and independence (Lord et al., 2020). These priorities suggest value in developing stronger liaison relationships between specialist autism services and other health and social care providers.

It is important to note the adaptations reported by previous research that were not priority adaptations in this study. These included: involvement of family members in therapeutic work, working on understanding emotions, utilising a behavioural approach, incorporating a range of concrete or creative methods such as role play, using idiosyncratic rating scales and incorporating special interests into therapy (Moree \& Davis III, 2010; Spain et al., 2015; Walters et al., 2016; Cooper et al., 2018; Ainsworth et al., 2020). Several of these modifications, for example building emotional understanding, were listed by participants but were lower in salience and therefore not considered a priority for full service design. These discrepancies are likely explained by the participant sample being a full multidisciplinary team, in contrast to a narrower focus on therapy practice (Spain \& Happé, 2020).

\section{Limitations and Directions for Future Research}

The study requires replication beyond one service. The sample size of 15 was sufficient due to the demonstrated high knowledge scores and cultural consensus, but was lower than recommended for the method (Weller \& Romney, 1988) and should be replicated. Future research would benefit from supplementing the brief list responses with exploratory qualitative methods. Finally, research on tailoring therapeutic services for autism must seek to actively involve the autistic community (Gillespie-Lynch et al., 2017). These practical recommendations for tailoring current care provision will also need to respond to developments in our understanding of the spectrum condition, with consideration of diversifying needs and increasing prevalence (Frith \& Happé, 2005; Campisi et al., 2018).

Strengths of the study include the freelisting design, allowing for focused gathering of qualitative data to examine the extent to which knowledge is shared among individuals in a specialist setting (Schrauf \& Sanchez, 2008; Romney et al., 1986), praised for being simple and efficacious in nature and suitable for pressed clinical environments. The study sought detailed examples of current and achievable practice. Further strengths included the representative multidisciplinary sample, sampling from a service delivering NHS and private contracts and adhering to best practice diagnostic processes (NICE, 2013, 2016; Lord et al., 2020); the stringent cross-checking procedures in the analysis that strengthened the validity and generalisability of the findings to healthcare services in the UK. The suggested adaptations are readily implementable by all professionals and services caring for autistic people. This study is an important addition to the research and practice literature on tailoring therapeutic services for autistic clients.

\section{Conclusion}

In summary, this study contributes to the limited literature available that guides practitioners when adapting services for autistic people (NICE, 2013, 2016). The findings agree with and replicate prior recommendations (Spain et al., 2015; Cooper et al., 2018; Ainsworth et al., 2020; Maddox et al., 2020). Self-reported recommendations are added from clinicians, of multiple disciplines, delivering a specialist autism diagnostic and therapy service across the age range ${ }^{1}$.

Authors' Contributions All authors contributed to the study conception, design and material preparation. Data collection was performed by MiljaLeea Bergenheim, Georgina Mahoney and Lucy Chamberlain. Analysis was performed by all authors. The first draft of the manuscript was written by Stephanie Petty and all authors commented on previous versions of the manuscript. All authors read and approved the final manuscript.

Funding The authors did not receive support from any organization for the submitted work.

Availability of Data and Material The datasets generated during the current study are available from the corresponding author on reasonable request.

Code Availability Not applicable.

\section{Declarations}

Conflicts of Interest/Competing Interests The authors have no relevant financial or non-financial interests to disclose.

Ethics Approval Approval was obtained from the ethics committee of University of York and The Retreat York. The procedures used in this study adhere to the tenets of the Declaration of Helsinki.

Consent to Participate Informed consent was obtained from all individual participants included in the study.

Consent to Publish All participants gave informed consent for publication of anonymous data.

\footnotetext{
${ }^{1}$ The authors have chosen to use identity-first language, 'autistic' or 'autistic people'; this is an attempt to be led by the preferences of autistic people and has been chosen with careful consideration and consultation.
} 
Open Access This article is licensed under a Creative Commons Attribution 4.0 International License, which permits use, sharing, adaptation, distribution and reproduction in any medium or format, as long as you give appropriate credit to the original author(s) and the source, provide a link to the Creative Commons licence, and indicate if changes were made. The images or other third party material in this article are included in the article's Creative Commons licence, unless indicated otherwise in a credit line to the material. If material is not included in the article's Creative Commons licence and your intended use is not permitted by statutory regulation or exceeds the permitted use, you will need to obtain permission directly from the copyright holder. To view a copy of this licence, visit http://creativecommons.org/licenses/by/4.0/.

\section{References}

Ainsworth, K., Robertson, A. E., Welsh, H., Day, M., Watt, J., Barry, F., Stanfield, A., \& Melville, C. (2020). Anxiety in adults with autism: Perspectives from practitioners. Research in Autism Spectrum Disorders, 69, 101457. https://doi.org/10.1016/j.rasd.2019.101457.

American Psychiatric Association. (2013). Diagnostic and statistical manual of mental disorders (5th ed.). Author.

Barg, F. K., Huss-Ashmore, R., Wittink, M. N., Murray, G. F., Bogner, H. R., \& Gallo, J. J. (2006). A mixed-methods approach to understanding loneliness and depression in older adults. The Journals of Gerontology Series B: Psychological Sciences and Social Sciences, 61(6), 329-339. https://doi.org/10.1093/geronb/61.6.S329.

Bearss, K., Taylor, C. A., Aman, M. G., Whittemore, R., Lecavalier, L., Miller, J., Pritchett, J., Green, B., \& Scahill, L. (2016). Using qualitative methods to guide scale development for anxiety in youth with autism spectrum disorder. Autism, 20(6), 663-672. https://doi.org/ $10.1177 / 1362361315601012$.

Beggiato, A., Peyre, H., Maruani, A., Scheid, I., Rastam, M., Amsellem, F., Gillberg, C. I., Leboyer, M., Bourgeron, T., Gillberg, C., \& Delorme, R. (2017). Gender differences in autism spectrum disorders: Divergence among specific core symptoms. Autism Research, 10(4), 680-689. https://doi.org/10.1002/aur.1715.

Bird, G., \& Cook, R. (2013). Mixed emotions: The contribution of alexithymia to the emotional symptoms of autism. Translational Psychiatry, 3(7), 1-8. https://doi.org/10.1038/tp.2013.61.

Borgatti, S. (1996a). ANTHROPAC 4.0 Analytic Technologies. Natick.

Borgatti, S. (1996b). ANTHROPAC 4.0 methods guide. Analytic Technologies.

Boulter, C., Freeston, M., South, M., \& Rodgers, J. (2014). Intolerance of uncertainty as a framework for understanding anxiety in children and adolescents with autism spectrum disorders. Journal of Autism and Developmental Disorders, 44(6), 1391-1402. https://doi.org/ 10.1007/s10803-013-2001-x.

Buescher, A. V., Cidav, Z., Knapp, M., \& Mandell, D. S. (2014). Costs of autism spectrum disorders in the United Kingdom and the United States. JAMA Pediatrics, 168(8), 721-728. https://doi.org/10.1001/ jamapediatrics.2014.210.

Cadman, T., Eklund, H., Howley, D., Hayward, H., Clarke, H., Findon, J., Xenitidis, K., Murphy, D., Asherson, P., \& Glaser, K. (2012). Caregiver burden as people with autism spectrum disorder and attention-deficit/hyperactivity disorder transition into adolescence and adulthood in the United Kingdom. Journal of the American Academy of Child \& Adolescent Psychiatry, 51(9), 879-888. https://doi.org/10.1016/j.jaac.2012.06.017.

Campisi, L., Imran, N., Nazeer, A., Skokauskas, N., \& Azeem, M. W. (2018). Autism spectrum disorder. British Medical Bulletin, 127(1), 91-900. https://doi.org/10.1093/bmb/ldy026.
Centers for Disease Control and Prevention. (2020). Data and statistics on autism spectrum disorder. Retrieved from: https://www.cdc.gov/ ncbddd/autism/data.html

Cooper, K., Loades, M. E., \& Russell, A. (2018). Adapting psychological therapies for autism. Research in Autism Spectrum Disorders, 45, 43-50. https://doi.org/10.1016/j.rasd.2017.11.002.

Crane, L., Goddard, L., \& Pring, L. (2009). Sensory processing in adults with autism spectrum disorders. Autism, 13(3), 215-228. https://doi. org $/ 10.1177 / 1362361309103794$

Dean, M., Harwood, R., \& Kasari, C. (2017). The art of camouflage: Gender differences in the social behaviors of girls and boys with autism spectrum disorder. Autism, 21(6), 678-689. https://doi.org/ $10.1177 / 1362361316671845$.

Department of Health. (2014). 'Think autism': An update to the government adult autism strategy. Retrieved from: https://www.gov.uk/ government/publications/think-autism-an-update-to-thegovernment-adult-autism-strategy

Dewinter, J., De Graaf, H., \& Begeer, S. (2017). Sexual orientation, gender identity, and romantic relationships in adolescents and adults with autism spectrum disorder. Journal of Autism and Developmental Disorders, 47(9), 2927-2934. https://doi.org/10. 1007/s10803-017-3199-9.

Frith, U., \& Happé, F. (2005). Autism spectrum disorder. Current Biology, 15(19), R786-R790. https://doi.org/10.1016/j.cub.2005.09.032.

Gillespie-Lynch, K., Kapp, S. K., Brooks, P. J., Pickens, J., \& Schwartzman, B. (2017). Whose expertise is it? Evidence for autistic adults as critical autism experts. Frontiers in Psychology, 8, 1-14. https://doi.org/10.3389/fpsyg.2017.00438.

Happé, F., Ronald, A., \& Plomin, R. (2006). Time to give up on a single explanation for autism. Nature Neuroscience, 9(10), 1218-1220. https://doi.org/10.1038/nn1770.

Hedley, D., Uljarević, M., Wilmot, M., Richdale, A., \& Dissanayake, C. (2018). Understanding depression and thoughts of self-harm in autism: A potential mechanism involving loneliness. Research in Autism Spectrum Disorders, 46, 1-7. https://doi.org/10.1016/j.rasd.2017.11.003.

Hofvander, B., Delorme, R., Chaste, P., Nydén, A., Wentz, E., Ståhlberg, O., et al. (2009). Psychiatric and psychosocial problems in adults with normal-intelligence autism spectrum disorders. $B M C$ Psychiatry, 9(35), 1-9. https://doi.org/10.1186/1471-244X-9-35.

Hull, L., Petrides, K. V., \& Mandy, W. (2020). The female autism phenotype and camouflaging: A narrative review. Review Journal of Autism and Developmental Disorders, 7, 1-12. https://doi.org/10. 1007/s40489-020-00197-9.

Kraper, C. K., Kenworthy, L., Popal, H., Martin, A., \& Wallace, G. L. (2017). The gap between adaptive behavior and intelligence in autism persists into young adulthood and is linked to psychiatric comorbidities. Journal of Autism and Developmental Disorders, 47(10), 3007-3017. https://doi.org/10.1007/s10803-017-3213-2.

Leekam, S. R., Nieto, C., Libby, S. J., Wing, L., \& Gould, J. (2007). Describing the sensory abnormalities of children and adults with autism. Journal of Autism and Developmental Disorders, 37(5), 894-910. https://doi.org/10.1007/s10803-006-0218-7.

Lever, A. G., \& Geurts, H. M. (2016). Psychiatric co-occurring symptoms and disorders in young, middle-aged, and older adults with autism spectrum disorder. Journal of Autism and Developmental Disorders, 46(6), 1916-1930. https://doi.org/10.1007/s10803-016-2722-8.

Loomes, R., Hull, L., \& Mandy, W. P. L. (2017). What is the male-to-female ratio in autism spectrum disorder? A systematic review and meta-analysis. Journal of the American Academy of Child \& Adolescent Psychiatry, 56(6), 466-474. https://doi.org/10.1016/j.jaac.2017.03.013.

Lord, C., Brugha, T. S., Charman, T., Cusack, J., Dumas, G., Frazier, T., et al. (2020). Autism spectrum disorder. Nature Reviews Disease Primers, 6(1), 1-23.

Lugo-Marín, J., Magán-Maganto, M., Rivero-Santana, A., Cuellar-Pompa, L., Alviani, M., Jenaro-Rio, C., et al. (2019). Prevalence of psychiatric disorders in adults with autism spectrum disorder: A systematic review 
and meta-analysis. Research in Autism Spectrum Disorders, 59, 22-33. https://doi.org/10.1016/j.psychres.2020.112922.

Lumley, M. A., Neely, L. C., \& Burger, A. J. (2007). The assessment of alexithymia in medical settings: Implications for understanding and treating health problems. Journal of Personality Assessment, 89(3), 230-246. https://doi.org/10.1080/00223890701629698.

Maddox, B. B., Crabbe, S., Beidas, R. S., Brookman-Frazee, L., Cannuscio, C. C., Miller, J. S., Nicolaidis, C., \& Mandell, D. S. (2020). "I wouldn't know where to start": Perspectives from clinicians, agency leaders, and autistics adults on improving community mental health services for autistic adults. Autism, 24(4), 919-930.

Maisel, M. E., Stephenson, K. G., South, M., Rodgers, J., Freeston, M. H., \& Gaigg, S. B. (2016). Modeling the cognitive mechanisms linking autism symptoms and anxiety in adults. Journal of Abnormal Psychology, 125(5), 692-703. https://doi.org/10.1037/abn0000168.

Martinez Tyson, D. D., Castañeda, H., Porter, M., Quiroz, M., \& Carrion, I. (2011). More similar than different? Exploring cultural models of depression among Latino immigrants in Florida. Depression Research and Treatment, 2011, 1-12. https://doi.org/10.1155/2011/564396.

Mazefsky, C. A., Herrington, J., Siegel, M., Scarpa, A., Maddox, B. B., Scahill, L., \& White, S. W. (2013). The role of emotion regulation in autism spectrum disorder. Journal of the American Academy of Child \& Adolescent Psychiatry, 52(7), 679-688. https://doi.org/10. 1016/j.jaac.2013.05.006.

Moree, B. N., \& Davis III, T. E. (2010). Cognitive-behavioral therapy for anxiety in children diagnosed with autism spectrum disorders: Modification trends. Research in Autism Spectrum Disorders, 4(3), 346-354. https://doi.org/10.1016/j.rasd.2009.10.015.

Murphy, D., Glaser, K., Hayward, H., Cadman, T., Findon, J., Woodhouse, E., et al. (2018). Crossing the divide: A longitudinal study of effective treatments for people with autism and attention deficit hyperactivity disorder across the lifespan. Programme Grants for Applied Research, 6(2), 1-240. https://doi.org/10.3310/pgfar06020.

National Institute for Health and Care Excellence. (2013). Autism spectrum disorder in under 19s: Support and management [CG170]. Retrieved from: https://www.nice.org.uk/Guidance/CG170

National Institute for Health and Care Excellence. (2016). Autism spectrum disorder in adults: Diagnosis and management [CG142]. Retrieved from: https://www.nice.org.uk/guidance/cg142

Perihan, C., Burke, M., Bowman-Perrott, L., Bicer, A., Gallup, J., Thompson, J., \& Sallese, M. (2019). Effects of cognitive behavioral therapy for reducing anxiety in children with high functioning ASD: A systematic review and meta-analysis. Journal of Autism and Developmental Disorders, 50(6), 1958-1972. https://doi.org/10. 1007/s10803-019-03949-7.

Petty, S., Dening, T., Griffiths, A., \& Coleston, D. M. (2020). Meeting the emotional needs of hospital patients with dementia: A freelisting study with ward staff. The Gerontologist, 60(1), 155-164. https:// doi.org/10.1093/geront/gny151.

Renaud, J., Russell, J. J., \& Myhr, G. (2014). Predicting who benefits most from cognitive-behavioral therapy for anxiety and depression. Journal of Clinical Psychology, 70(10), 924-932. https://doi.org/10. 1002/jclp.22099.

Romney, A. K., Weller, S. C., \& Batchelder, W. H. (1986). Culture as consensus: A theory of culture and informant accuracy. American Anthropologist, 88(2), 313-338. https://doi.org/10.1525/aa.1986. 88.2.02a00020.

Rydzewska, E., Hughes-McCormack, L. A., Gillberg, C., Henderson, A., MacIntyre, C., Rintoul, J., \& Cooper, S. A. (2019). Prevalence of sensory impairments, physical and intellectual disabilities, and mental health in children and young people with self/proxy-reported autism:
Observational study of a whole country population. Autism, 23(5), 1201-1209. https://doi.org/10.1177/1362361318791279.

Schrauf, R. W., \& Sanchez, J. (2008). Using freelisting to identify, assess, and characterize age differences in shared cultural domains. The Journals of Gerontology Series B: Psychological Sciences and Social Sciences, 63(6), 385-393. https://doi.org/10.1093/geronb/63.6.s385.

Simonoff, E., Pickles, A., Charman, T., Chandler, S., Loucas, T., \& Baird, G. (2008). Psychiatric disorders in children with autism spectrum disorders: Prevalence, comorbidity, and associated factors in a population-derived sample. Journal of the American Academy of Child \& Adolescent Psychiatry, 47(8), 921-929. https://doi.org/10. 1097/CHI.0b013e318179964f.

Simpson, S. (2016). Checklist for autism-friendly environments. Retrieved from: https://www.nice.org.uk/guidance/cg142/ resources/endorsed-resource-checklist-for-autismfriendlyenvironments-2016-2665557037

Skagerberg, E., Di Ceglie, D., \& Carmichael, P. (2015). Brief report: Autistic features in children and adolescents with gender dysphoria. Journal of Autism and Developmental Disorders, 45(8), 2628-2632.

Smith, J. J., \& Borgatti, S. P. (1998). Salience counts - and so does accuracy: Correcting and updating a measure for free-list-item salience. Journal of Linguistic Anthropology, 7(2), 208-209. https:// doi.org/10.1525/jlin.1997.7.2.208.

Spain, D., \& Happé, F. (2020). How to optimise cognitive behaviour therapy (CBT) for people with autism spectrum disorders (ASD): A Delphi study. Journal of Rational-Emotive \& Cognitive-Behavior Therapy, 38, 184-208. https://doi.org/10.1007/s10942-019-00335-1.

Spain, D., Sin, J., Chalder, T., Murphy, D., \& Happé, F. (2015). Cognitive behaviour therapy for adults with autism spectrum disorders and psychiatric co-morbidity: A review. Research in Autism Spectrum Disorders, 9, 151-162. https://doi.org/10.1016/j.rasd.2014.10.019.

Uljarević, M., Richdale, A. L., McConachie, H., Hedley, D., Cai, R. Y., Merrick, H., et al. (2018). The hospital anxiety and depression scale: Factor structure and psychometric properties in older adolescents and young adults with autism spectrum disorder. Autism Research, 11(2), 258-269. https://doi.org/10.1002/aur.1872.

van Heijst, B. F., \& Geurts, H. M. (2015). Quality of life in autism across the lifespan: A meta-analysis. Autism, 19(2), 158-167. https://doi. org $/ 10.1177 / 1362361313517053$.

Walters, S., Loades, M., \& Russell, A. (2016). A systematic review of effective modifications to cognitive behavioural therapy for young people with autism spectrum disorders. Review Journal of Autism and Developmental Disorders, 3(2), 137-153. https://doi.org/10. 1007/s40489-016-0072-2.

Weller, S. C., \& Romney, A. K. (1988). Systematic data collection. Sage. https://doi.org/10.4135/9781412986069.

Wigham, S., Rodgers, J., South, M., McConachie, H., \& Freeston, M. (2015). The interplay between sensory processing abnormalities, intolerance of uncertainty, anxiety and restricted and repetitive behaviours in autism spectrum disorder. Journal of Autism and Developmental Disorders, 45(4), 943-952. https://doi.org/10. 1007/s10803-014-2248-x.

Wigham, S., Barton, S., Parr, J. R., \& Rodgers, J. (2017). A systematic review of the rates of depression in children and adults with highfunctioning autism spectrum disorder. Journal of Mental Health Research in Intellectual Disabilities, 10(4), 267-287. https://doi. org/10.1080/19315864.2017.1299267.

Publisher's Note Springer Nature remains neutral with regard to jurisdictional claims in published maps and institutional affiliations. 